\title{
Shirazi thyme (Zataria multiflora) extract can alleviate allergic rhinitis: a randomized clinical trial
}

\author{
Nazila Ariaee ${ }^{1}$, Maryam Panahi ${ }^{1}$, Mahdi Bakhshaee ${ }^{2}$, Jalal Ghorbani ${ }^{1}$, Yalda Ravanshad ${ }^{3}$, Reza Farid Hosseini ${ }^{1}$, \\ Alireza Ranjbar ${ }^{4}$, Farahzad Jabbari ${ }^{1}$ \\ ${ }^{1}$ Allergy Research Center, Mashhad University of Medical Sciences, Mashhad, Iran \\ Ear, Nose, and Throat Research Center, Imam Reza Hospital, Mashhad University of Medical Sciences, Mashhad, Iran \\ ${ }^{3}$ Clinical Research Development Units, Mashhad University of Medical Sciences, Mashhad, Iran \\ ${ }^{4}$ Research Institute of Interventional Allergology and Immunology, Bonn/Cologne, Germany
}

Adv Dermatol Allergol 2021; XXXVIII (3): 520-525

DOI: https://doi.org/10.5114/ada.2020.102295

\begin{abstract}
Introduction: Atopic diseases are global concerns in the today's industrialized world. Allergic rhinitis is the most common allergic condition affecting $20 \%$ of individuals. This disorder is associated with remarkable morbidity and rising healthcare expenditure.

Aim: Considering the anti-inflammatory properties of a plant Zataria multiflora (ZM) with the common name of Shirazi thyme, a randomized clinical trial was designed to evaluate the alleviation of the symptoms of allergic rhinitis. Material and methods: A total of 30 allergic rhinitis patients were randomly and equally assigned to experimental and control groups. Afterwards, the case group was treated with an extract of ZM and the control group with placebo for 2 months. Finally, the clinical signs and symptoms before and after the treatment according to the SNOT22 questionnaire were analysed.

Results: Comparing the symptoms of allergic rhinitis and an average score of SNOT22 questionnaire between the two groups before the intervention provided some difference, which was significantly greater after the treatment. Based on this questionnaire, our patients in the ZM syrup group had lower grades than before the treatment and experienced amelioration.

Conclusions: Regarding the significant effect of the ZM syrup in reducing symptoms of allergic rhinitis, its use is highly recommended. Since allergic rhinitis is a multifactorial condition, the use of herbal antioxidants along with conventional treatment would result in a more effective improvement of the disease.
\end{abstract}

Key words: allergic rhinitis, thyme, Zataria multiflora, herbal product.

\section{Introduction}

Allergic rhinitis is a common inflammatory disorder that affects 400 million individuals in all ages worldwide, particularly in developed countries [1]. Due to the increasing prevalence of atopic disorders in the 21 century, we will experience a dramatic proportion of patients with allergic rhinitis [2]. This disease is characterized by sneezing, clear rhinorrhoea, nasal congestion, and purities [3]. In addition to these symptoms, it usually affects well-being in some other ways including fatigue, sleep disorder, irritability, and difficulty in school and work or even in social relations [4]. Allergic rhinitis is mediated by the early and late phases of hypersensitivity response [5]. So, antihistamines, decongestion, and corticosteroids are the main elements of therapeutic strategy [6].

Zataria multiflora (ZM) is an edible thyme like a plant that is widely recognized with names of thyme or Avishan Shirazi [7]. This plant, which geographically grows in Iran, Pakistan, and Afghanistan, is a regular condiment in most commonplace foods [8]. The main components of ZM are Thymol and Carvacrol. In addition, $p$-Cymen is another abundant compound in ZM extracts [9]. ZM is not only a popular condiment but also is widely used in traditional medicine for analgesia, diarrhoea, infectious diseases, and gastrointestinal problems [10]. Modern

Address for correspondence: Farahzad Jabbari, Allergy Research Center, Mashhad University of Medical Sciences, Ghaem Hospital, Shariati Square, Mashhad, Iran, phone/fax: +98 51 38458769, e-mail: Jabbarif@mums.ac.ir Received: 25.05.2019, accepted: 20.02.2020 
investigations have proved its anti-inflammatory and anti-nociceptive effects because of the wide range of biological properties [8]. According to the increasing trend of allergic conditions and recent development in the field of herbal products [1, 11], a double-blind randomized control trial study was designed in this study to evaluate possible effects of the ZM syrup in the treatment of allergic rhinitis and alleviating the symptoms.

\section{Material and methods}

\section{Study population}

A total of 43 patients with a history of seasonal allergic rhinitis for at least 2 years and at least 1 skin prick test for common aeroallergen $[12,13]$ were eligible for the study. They were chosen according to the purposive sampling. All the patients were from the clinic of allergy, Qaem Hospital, Mashhad, Iran. The patients diagnosed with the allergic rhinitis from November to January 2013 were enrolled to avoid the effects of aeroallergen in this season. All patients were seen by two different allergists. The patients meet the criteria of allergy according to GLORIA (Global Resources in Allergy) [14].

To focus on thyme effects, the patients taking other herbal products were excluded from the study. Furthermore, patients with systemic disease, sinusitis, and pregnancy were also excluded. Those with antioxidant and anti-inflammatory treatments were excluded from the investigation as well. Finally, after removing patients who showed some side effects, 30 patients with allergic rhinitis were enrolled in this study. Fifteen individuals were administered the ZM syrup beside their conventional treatment and fifteen patients in the control group received placebo. The randomization system was the pocket system. All the patients were administered Cetirizine tablets and Flixonase spray. The dose of Cetirizine and Flixonase nasal spray was selected based on the severity of their disease. ZM syrup and placebo groups that were both equal in the appearance or taste were labelled with A (placebo group) and B (ZM syrup group), respectively. Neither the patients nor the physician was aware of the groups and their labels. Patients were randomly allocated to the ZM syrup group and placebo so that even the distracter did not know about A and B labels' ingredients.

The patients were evaluated before and after the treatment by a SNOT22 questionnaire containing 22 questions. Each question had a range of $0-5$ from "without any effect" to "very severe" [15].

\section{Preparation of the ZM syrup}

To prepare the ZM syrup, first, the ZM hydroalcoholic extract with a concentration of $20 \%$ was bought from Giah Essence (Gorgan, Iran). The ingredients of the ZM extract are presented in our previous article [16]. It was diluted to $37 \%$ with another ZM extract from the National Formulary
(Iran) to achieve the final concentration of Thymol $20.5 \mathrm{mg}$ per $100 \mathrm{ml}$ and Carvacrol $2.85 \mathrm{mg}$ per $100 \mathrm{ml}$ [16]. The syrup was prepared in $120 \mathrm{ml}$ bottles and patients received $10 \mathrm{ml}$ of the extract for each time and three times a day for 2 months. This protocol was also the same for the placebo group. All the patients in both groups were evaluated with the Sino-Nasal Outcome Test 22 (SNOT22) questionnaire before and after the treatment. The validity and reliability of the Persian version of SNOT22 was checked and confirmed in 2013 [17].

\section{Ethics approval and consent to participate}

The protocol of investigation was approved by the Ethics Committee of Mashhad University of Medical Sciences (code: IR.MUMS.REC 1393.74) and Iran Registry of Clinical Trials (code: IRCT2016121823235N6). All patients signed a written informed consent agreement.

\section{Statistical analysis}

Data analysis was carried out using SPSS software (version 16, USA). We used a $t$-test to compare the average of case and control groups. To analyse the normal distribution in two groups, the Kolmogorov-Smirnov test was applied. Due to the normal distribution of data in

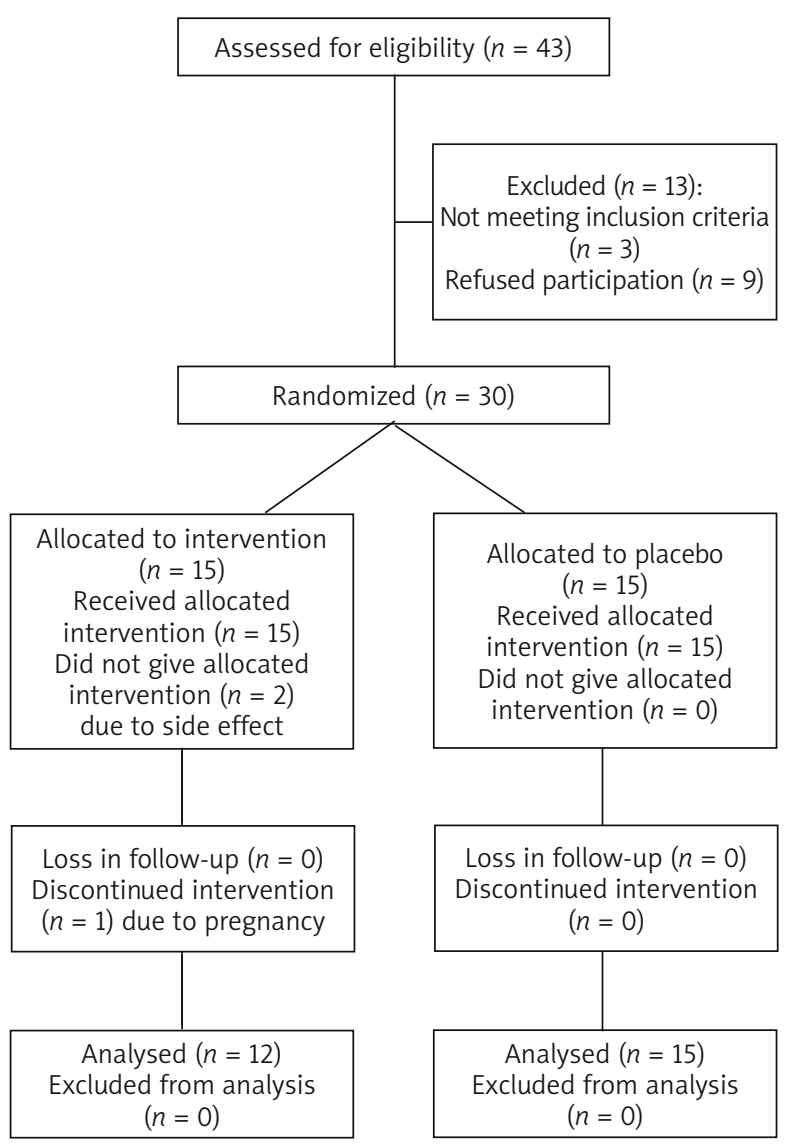

Figure 1. Consort flow diagram of the study 
two groups, we used Pair T-test to determine the differences. McNemar's and chi-squared $\left(\chi^{2}\right)$ tests were applied to analyse the qualitative parameters. The differences were considered to be significant at $p<0.05$.

\section{Results}

In the present study, two of enrolled patients had shown some side effects of thyme such as nausea, diarrhoea, and vomiting. Although the side effects were mild, these 2 patients were excluded and eliminated from the study. Besides, 1 patient due to other reasons discontinued participating in the investigation. Overall, the details can be seen in Consort flow diagram in Figure 1.

In this investigation, 30 patients with allergic rhinitis were enrolled of which 17 (56.7\%) were female and 13 (47.3\%) were male. The mean, minimum, and maximum ages of all patients who participated in this study were 33, 11-67 years, respectively. Since the patients were subdivided into the groups at random, each group consists of fifteen patients. Checking the age distribution within these two groups showed no statistically significant difference. Meanwhile, the sex distribution between the groups was checked, but no significant difference was obtained.

SNOT22 questionnaire was filled for the patients in both groups before and after the treatment. The average grades in groups $A$ and $B$ before treatment are shown in Table 1. In group A (placebo), the grades were lower than those in group B (ZM syrup). It means more severe patients were assigned to group A (placebo) accidentally. This happened by a sheer chance because the distributor did not have any information about the questionnaire grades or the severity of their disease.

Our study showed that both groups after the treatment obtained better grades than before treatment. However, the data in the placebo group were not significant after normalizing so that we had a declining score from $47.5 \pm 2$ to $37.7 \pm 2$. Meanwhile, in the ZM group, the SNOT22 average score fell from $32.9 \pm 9.7$ to $9.4 \pm 6$, which was significant ( $p=0.034)$. It was observed that the ZM syrup has stronger alleviatory effects than the placebo. Although all the parameters in SNOT22 were applied in total scoring, the most common issues and symptoms that patients complained about in the SNOT22 were analysed specifically to clarify how ZM can affect the severity of allergic rhinitis and SNOT22 scores.
The severity of sneezing between two groups before treatment did not show any significant difference $(p=0.650)$ but after the treatment, it differed significantly $(p=0.001)$. Treatment with the ZM syrup proved to be a significantly more effective remedy, so the severity of sneezing was alleviated after the intervention. Analysing each group before and after the treatment separately, it was observed that the placebo group did not achieve any significant amelioration compared on the first day $(p=0.125)$, while the ZM group reached a significant difference after 2 months' treatment with the ZM syrup in comparison with the first day $(p<0.01)$. The details can be seen in Table 2 .

Nasal congestion among patients in both groups was evaluated before and after the treatment. Data were statistically analysed by the $\chi^{2}$ test. The results showed a significant difference between groups before the treatment $(p=0.011)$. After the treatment, it was also observed that groups $A$ and $B$ were statistically different ( $p<0.001)$. Evaluating each group before and after the treatment with the sign test proved that only group $B$ achieved a significant difference after 2 months of treatment in comparison with the first day $(p<0.001)$. As can be seen in Table 3, it is statistically proved that the severity of nasal congestion was reduced in the ZM group slightly more than in the placebo group.

In assessing sleep disorders among patients, although no difference occurred before the treatment $(p=0.13)$, a significant difference was observed between two groups after the treatment $(p=0.006)$.

Furthermore, regarding the loss of smell and taste, the ZM syrup had no impact and the patients in both groups received similar scores before and after the intervention. The difference between the ZM group and the placebo group was analysed through $\chi^{2}$ and it was found not significant before the treatment on the first day $(p=0.44)$. Meanwhile, after the treatment, the difference between these two groups was not statistically significant $(p=0.56)$. After the intervention scores for the loss of taste and smell in each group were compared with their scores on the first day. This analysis, which was conducted via the sign test, proved that both groups had significant differences. The $p$-value for the ZM group was 0.001 and for the placebo group it was 0.016. The details can be seen in Table 2.

In the last part analysing the effect of allergic rhinitis on patients' work and school absence, it remained

Table 1. SNOT22 questionnaire grades in treatment with the ZM syrup and placebo before and after the treatment. Differences were considered to be significant when $p<0.05$

\begin{tabular}{|c|c|c|c|c|c|c|c|c|}
\hline \multirow[t]{2}{*}{ Groups } & \multicolumn{4}{|c|}{ Before treatment } & \multicolumn{4}{|c|}{ After treatment } \\
\hline & Min. & Max. & Mean \pm SD & $P$-value & Min. & Max. & Mean \pm SD & $P$-value \\
\hline Placebo & 16 & 91 & $47.5 \pm 22$ & \multirow{2}{*}{0.018} & 5 & 77 & $37.7 \pm 22$ & \multirow[t]{2}{*}{$<0.001$} \\
\hline ZM & 14 & 47 & $32 \pm 9.7$ & & 2 & 25 & $9.4 \pm 6$ & \\
\hline$P$-value & 0.034 & & & & & & & \\
\hline
\end{tabular}


Table 2. SNOT22 questioner grades in treatment with ZM syrup and placebo before and after the treatment. All the data are from the patients who had the symptoms

\begin{tabular}{|c|c|c|c|c|c|c|c|c|c|c|c|c|c|c|}
\hline \multirow[b]{2}{*}{ Scores } & \multicolumn{7}{|c|}{ Before intervention } & \multicolumn{7}{|c|}{ After intervention } \\
\hline & 0 & 1 & 2 & 3 & 4 & 5 & $\begin{array}{l}\text { Total } \\
\text { score }\end{array}$ & 0 & 1 & 2 & 3 & 4 & 5 & $\begin{array}{l}\text { Total } \\
\text { score }\end{array}$ \\
\hline \multicolumn{15}{|c|}{ Severity of sneezing: } \\
\hline Placebo & $\begin{array}{c}2 \\
6.7 \%\end{array}$ & $\begin{array}{c}3 \\
10 \%\end{array}$ & $\begin{array}{c}5 \\
16 \% \\
\end{array}$ & $\begin{array}{c}1 \\
\% 3.3\end{array}$ & $\begin{array}{c}2 \\
6 \%\end{array}$ & $\begin{array}{c}2 \\
6 \%\end{array}$ & 31 & $\begin{array}{c}5 \\
16.7 \%\end{array}$ & $\begin{array}{c}1 \\
3.3 \%\end{array}$ & $\begin{array}{l}0 \\
0\end{array}$ & $\begin{array}{c}7 \\
23 \%\end{array}$ & $27.6 \%$ & $\begin{array}{l}0 \\
0\end{array}$ & 30 \\
\hline ZM & $\begin{array}{l}0 \\
0\end{array}$ & $\begin{array}{l}0 \\
0\end{array}$ & $\begin{array}{l}0 \\
0\end{array}$ & $\begin{array}{c}4 \\
13 \% \\
\end{array}$ & $\begin{array}{c}4 \\
13 \% \\
\end{array}$ & $\begin{array}{c}7 \\
23 \% \\
\end{array}$ & 63 & $\begin{array}{c}2 \\
6 \% \\
\end{array}$ & $\begin{array}{c}6 \\
20 \% \\
\end{array}$ & $\begin{array}{c}5 \\
16.7 \% \\
\end{array}$ & $\begin{array}{l}0 \\
0 \\
\end{array}$ & $\begin{array}{l}0 \\
0\end{array}$ & $\begin{array}{c}2 \\
6 \% \\
\end{array}$ & 26 \\
\hline \multicolumn{15}{|c|}{ Severity of congestion: } \\
\hline Placebo & $\begin{array}{c}3 \\
10 \%\end{array}$ & $\begin{array}{c}3 \\
10 \%\end{array}$ & $\begin{array}{c}5 \\
16 \%\end{array}$ & $\begin{array}{c}3 \\
10 \%\end{array}$ & $\begin{array}{c}1 \\
3.3 \%\end{array}$ & $\begin{array}{l}0 \\
0\end{array}$ & 34 & $\begin{array}{c}9 \\
30 \%\end{array}$ & $\begin{array}{c}3 \\
10 \%\end{array}$ & $\begin{array}{c}2 \\
6.7 \%\end{array}$ & $\begin{array}{c}1 \\
3.3 \%\end{array}$ & $\begin{array}{l}0 \\
0\end{array}$ & $\begin{array}{l}0 \\
0\end{array}$ & 6 \\
\hline ZM & $\begin{array}{l}0 \\
0\end{array}$ & $\begin{array}{l}0 \\
0\end{array}$ & $\begin{array}{l}0 \\
0\end{array}$ & $\begin{array}{c}2 \\
6.7 \% \\
\end{array}$ & $\begin{array}{c}8 \\
26.7 \% \\
\end{array}$ & $\begin{array}{c}5 \\
16.7 \% \\
\end{array}$ & 63 & $\begin{array}{c}1 \\
3.3 \% \\
\end{array}$ & $\begin{array}{c}6 \\
20 \% \\
\end{array}$ & $\begin{array}{c}1 \\
3.3 \% \\
\end{array}$ & $\begin{array}{c}4 \\
13.3 \% \\
\end{array}$ & $\begin{array}{c}2 \\
6.7 \% \\
\end{array}$ & $\begin{array}{c}1 \\
3.3 \% \\
\end{array}$ & 33 \\
\hline \multicolumn{15}{|c|}{ The severity of Rhino ray: } \\
\hline Placebo & $\begin{array}{c}1 \\
3.3 \% \\
\end{array}$ & $\begin{array}{c}2 \\
6.7 \% \\
\end{array}$ & $\begin{array}{c}5 \\
16.7 \% \\
\end{array}$ & $\begin{array}{c}3 \\
10 \% \\
\end{array}$ & $\begin{array}{c}4 \\
13.3 \% \\
\end{array}$ & $\begin{array}{l}0 \\
0\end{array}$ & 46 & $\begin{array}{c}6 \\
20 \% \\
\end{array}$ & $\begin{array}{c}3 \\
10 \% \\
\end{array}$ & $\begin{array}{c}3 \\
10 \% \\
\end{array}$ & $\begin{array}{l}0 \\
0 \\
\end{array}$ & $\begin{array}{c}3 \\
10 \% \\
\end{array}$ & $\begin{array}{l}0 \\
0 \\
\end{array}$ & 21 \\
\hline ZM & $\begin{array}{l}0 \\
0\end{array}$ & $\begin{array}{l}0 \\
0\end{array}$ & $\begin{array}{l}0 \\
0\end{array}$ & $\begin{array}{l}0 \\
0\end{array}$ & $\begin{array}{c}9 \\
30 \%\end{array}$ & $\begin{array}{c}6 \\
20 \% \\
\end{array}$ & 66 & $\begin{array}{c}2 \\
6.7\end{array}$ & $\begin{array}{c}5 \\
16.7 \% \\
\end{array}$ & $\begin{array}{c}4 \\
13.3 \% \\
\end{array}$ & $\begin{array}{c}2 \\
6.7 \% \\
\end{array}$ & $\begin{array}{c}1 \\
3.3 \% \\
\end{array}$ & $\begin{array}{c}1 \\
3.3 \% \\
\end{array}$ & 28 \\
\hline \multicolumn{15}{|c|}{ Loss of taste and smell: } \\
\hline Placebo & $\begin{array}{c}1 \\
3.3 \%\end{array}$ & $\begin{array}{c}2 \\
6.7 \%\end{array}$ & $\begin{array}{c}1 \\
3.3 \%\end{array}$ & $\begin{array}{c}5 \\
16.7 \%\end{array}$ & $\begin{array}{l}0 \\
0\end{array}$ & $\begin{array}{c}6 \\
20 \%\end{array}$ & 49 & $\begin{array}{c}2 \\
6.7 \%\end{array}$ & $\begin{array}{c}4 \\
13.3 \%\end{array}$ & $\begin{array}{c}3 \\
10 \%\end{array}$ & $\begin{array}{l}0 \\
0\end{array}$ & $\begin{array}{c}1 \\
3.3 \%\end{array}$ & $\begin{array}{c}2 \\
6.7 \%\end{array}$ & 24 \\
\hline ZM & $\begin{array}{l}0 \\
0\end{array}$ & $\begin{array}{l}0 \\
0\end{array}$ & $\begin{array}{l}0 \\
0\end{array}$ & $\begin{array}{c}2 \\
6.7 \%\end{array}$ & $\begin{array}{c}2 \\
6.7 \%\end{array}$ & $\begin{array}{c}11 \\
36.7 \%\end{array}$ & 69 & $\begin{array}{l}0 \\
0\end{array}$ & $\begin{array}{c}3 \\
10 \%\end{array}$ & $\begin{array}{c}1 \\
3.3 \%\end{array}$ & $\begin{array}{c}2 \\
6.7 \%\end{array}$ & $\begin{array}{c}1 \\
3.3 \%\end{array}$ & $\begin{array}{c}8 \\
26.8 \%\end{array}$ & 53 \\
\hline \multicolumn{15}{|c|}{ Sleep disorder: } \\
\hline Placebo & $\begin{array}{c}5 \\
6.7 \%\end{array}$ & $\begin{array}{c}1 \\
3.3 \%\end{array}$ & $\begin{array}{c}0 \\
0 \%\end{array}$ & $\begin{array}{c}3 \\
10 \%\end{array}$ & $\begin{array}{c}4 \\
13.3 \%\end{array}$ & $\begin{array}{c}2 \\
6.7 \%\end{array}$ & 36 & $\begin{array}{c}5 \\
16.7 \%\end{array}$ & $\begin{array}{c}2 \\
6.7 \%\end{array}$ & $\begin{array}{c}1 \\
3.3 \%\end{array}$ & $\begin{array}{c}3 \\
10 \%\end{array}$ & $\begin{array}{c}4 \\
13.3 \%\end{array}$ & $\begin{array}{l}0 \\
0\end{array}$ & 28 \\
\hline ZM & $\begin{array}{c}9 \\
30 \%\end{array}$ & $\begin{array}{c}2 \\
6.7 \%\end{array}$ & $\begin{array}{c}2 \\
6.7 \%\end{array}$ & $\begin{array}{c}1 \\
3.3 \%\end{array}$ & $\begin{array}{c}1 \\
3.3 \%\end{array}$ & $\begin{array}{l}0 \\
0\end{array}$ & 15 & $\begin{array}{c}13 \\
43.3 \%\end{array}$ & $\begin{array}{c}2 \\
6.7\end{array}$ & $\begin{array}{l}0 \\
0\end{array}$ & $\begin{array}{l}0 \\
0\end{array}$ & $\begin{array}{l}0 \\
0\end{array}$ & $\begin{array}{l}0 \\
0\end{array}$ & 17 \\
\hline
\end{tabular}

unchanged and it was observed to be the same as pretreatment in both groups. The details are shown in Table 3.

\section{Discussion}

Our study proved that the ZM syrup was successful in alleviating allergic rhinitis symptoms. SNOT22 results showed that parameters including the severity of sneezing and sleep disorder were alleviated in patients who used the ZM syrup. Evaluating nasal congestion revealed a slight reduction in the placebo group. As can be concluded from Table 2, the number of patients who experienced very severe nasal congestion reduced more dramatically in the ZM group than in the placebo group and a significant change was reported.

It was observed that although we had some significant results in the ZM syrup group compared with patients who received a placebo, this improvement did not affect work and school absence of the patients very much. Patients' work and school absence, which remained unchanged, may be related to lack of the ZM syrup effect in the general health. This result is in line with the general results of SNOT22 in the first look without normalizing and/or considering SNOT22 parameters separately. Meanwhile, it can be inferred that this occurs due to a psychological issue. With a larger study population with the equal severity of patients in case and control groups, it can be clarified that despite the improvement in the placebo group in some cases, the patients in the ZM syrup group improved significantly and a high effectiveness was shown. The improvement in the placebo group might take place due to the placebo effect. Randomized control trial studies only with placebo control can reach the gold standard and provide the highest level of evidence in clinical research [18]; it was proved that the placebo effect usually can happen by the psychological concept of the therapy. It sometimes depends on a variety of factors such as the individual characteristics of participants and the amount of information that they receive [19].

Moreover, during the investigation, patients with more severe symptoms were placed accidently in the placebo group, which explains the improvement in the placebo group. Also, since patients in the placebo group 
Table 3. Frequency of patients' work and school absence on the first day of investigation and after 2 months; Intervention with the ZM syrup is in the ZM group and the placebo is clarified in the placebo group

\begin{tabular}{lcccc}
\hline \multirow{2}{*}{ Groups } & \multicolumn{4}{c}{ Work and school absence $n$ (\%) } \\
\cline { 2 - 5 } & \multicolumn{2}{c}{ Before treatment } & \multicolumn{2}{c}{ After treatment } \\
\cline { 2 - 5 } & No & Yes & No & Yes \\
\hline Placebo & $9(30)$ & $6(20)$ & $13(43.3)$ & $2(6.7)$ \\
\hline ZM & $10(33.3)$ & $5(16.7)$ & $13(43.3)$ & $2(6.7)$ \\
\hline Total & $19(63)$ & $11(37.6)$ & $26(86.7)$ & $4(13.3)$ \\
\hline$P$-value & \multicolumn{3}{c}{0.7} & \multicolumn{3}{c}{1} \\
\hline
\end{tabular}

also were administered standard treatment, it is expected that their symptoms are ameliorated by starting the therapy. Since patients with allergic rhinitis rarely experience a complete cure, the ZM syrup was added to the standard therapy of the ZM group. On the other hand, the placebo group has the potential for the Hawthorne effect. Hawthorne effect concerns the consequent awareness of being studied and possible effects on the behaviours [20]. Hence, it can influence participants by the knowledge of being observed or studied, leading to reacting close to researcher's expectations [21].

Overall, many other researchers have attempted to assess the significance of ZM for different inflammatory issues including its remarkable upside on tracheal smooth muscle through a competitive antagonistic effect on histamine $\mathrm{H} 1$ receptors. The results of these studies highlighted the stimulatory effect of the extract on $\beta$-adrenergic receptors and perhaps a blocking effect on muscarinic receptors [22]. In another study, it was reported that this plant can play an equal role as Dexamethasone or even better in modulating serum levels of phospholipase A2, histamine, and nitric oxide in sensitized guinea pigs [7]. This research was done on guinea pigs so they did not apply the SNOT22 questionnaire. Since Avishan Shirazi grows only in the study area, there are no similar data to compare SNOT22 results. In general, ZM holds promise as anti-allergy agents capable of influencing various biological pathways and cells in the immune response and deserves further investigation.

A study of 2014 proved that Carvacrol as the main constituent of ZM has an inhibitory effect on lung inflammation in sensitized guinea pigs. They indicated that in addition to lung pathology, Carvacrol may have a profound impact on IgE and eosinophil peroxidase levels and differentiate WBC in the animal model [23]. All these data support the theory that this plant had an immune-modulatory effect via changing the profile of cytokines secretion in different ways including increasing IFN- $\gamma$ while decreasing IL-4 to interfere with Th1/Th2 balance through enhancing the ratio of IFN- $\gamma$ to IL-4. So, it might be a therapeutic value for inflammatory and atopic disease or some infectious disease. In a large number of these conditions, there is a need for a key factor to balance Th1/ Th2 to avoid allergic unpleasant drawbacks [24]. Meanwhile, in a parallel study, we checked the expression level of some cytokine in these patients and found the key role of IL-17 in this regard. In a previous study, no significant difference was found in cytokine expression between the two groups before the treatment. Meanwhile, after the treatment, no significant differences were found for IL-10, TGF- $\beta$, and FOXP3. On the other hand, IL-17 expression the ZM group was significantly lower than the control group [16]. Nevertheless, many other cytokines can fluctuate during improving allergic diseases even with changing diet $[25,26]$. Our investigation as a randomized control trial for allergic rhinitis can support the marvellous idea of administering the ZM syrup, which contains Carvacrol and other helpful ingredients for diseases such as allergic asthma and common colds. Beside indicating the effect of the ZM syrup our investigation had some limitations including a lack of higher number of enrolled subjects and unequal distribution of the severity in the groups, which occurred by accident.

\section{Conclusions}

The present investigation proved the therapeutic effect of the ZM in the improvement of allergic rhinitis in the enrolled patients and alleviation of the associated symptoms such as nasal congestion severity of sneezing. Considering that this plant is widespread in the southwest of Asia, particularly in Iran, and is a well-known cost-effective folk remedy, it would be easily accepted by patients. Hence, it is highly recommended as a conventional treatment of allergic rhinitis and other inflammatory and allergic diseases. Furthermore, it may lead to avoid adverse side effects of corticosteroids and other therapeutic agents by reducing the effective dose of conventional drugs.

\section{Acknowledgments}

The authors thank Roghaye Paidar for her sincere collaboration. Nazila Ariaee and Maryam Panahi are equivalent as the first author, and just sorted alphabetically.

This study was performed with the financial support of the research deputy director of Mashhad University of Medical Sciences (grant number: 910801).

\section{Conflict of interest}

The authors declare no conflict of interest.

\section{References}

1. Greiner AN, Hellings PW, Rotiroti G, Scadding GK. Allergic rhinitis. Lancet 2012; 378: 2112-22. 
2. De Marco R, Cappa V, Accordini S, et al. Trends in the prevalence of asthma and allergic rhinitis in Italy between 1991 and 2010. Eur Respir J 2012; 39: 883-92.

3. Wheatley LM, Togias A. Allergic rhinitis. N Engl J Med 2015; 372: 456-63.

4. Bousquet PJ, Demoly P, Devillier P, et al. Impact of allergic rhinitis symptoms on quality of life in primary care. Int Arch Allergy Immunol 2012; 160: 393-400.

5. Rondón C, Campo P, Togias A, et al. Local allergic rhinitis: concept, pathophysiology, and management. J Allergy Clin Immunol 2012; 129: 1460-7.

6. Braido F, Scichilone N, Lavorini F, et al. Manifesto on small airway involvement and management in asthma and chronic obstructive pulmonary disease: an Interasma (Global Asthma Association-GAA) and World Allergy Organization (WAO) document endorsed by Allergic Rhinitis and its Impact on Asthma (ARIA) and Global Allergy and Asthma European Network (GA 2 LEN). Asthma Res Pract 2016; 2: 12.

7. Boskabady MH, Jalali S, Farkhondeh T, Byrami G. The extract of Zataria multiflora affect tracheal responsiveness, serum levels of NO, nitrite, PLA2, TP and histamine in sensitized Guinea pigs. J Ethnopharmacol 2014; 156: 301-8.

8. Sajed H, Sahebkar A, Iranshahi M. Zataria multiflora Boiss. (Shirazi thyme) - an ancient condiment with modern pharmaceutical uses. J Ethnopharmacol 2013; 145: 686-98.

9. Saei-Dehkordi SS, Tajik H, Moradi M, Khalighi-Sigaroodi F. Chemical composition of essential oils in Zataria multiflora Boiss. from different parts of Iran and their radical scavenging and antimicrobial activity. Food Chem Toxicol 2010; 48: 1562-7.

10. Ghasemi Dehkordi N. Iranian herbal pharmacopoeia. Ministry of Health Pub Tehran 2002; 1: 105.

11. Ariaee-Nasab N, Vahedi Z, Vahedi F. Inhibitory effects of cinnamon-water extract on human tumor cell lines. Asian Pac J Trop Dis 2014; 4: S975-8.

12. Ariaee N, Varasteh A, Jabbari Azad F, Sankian M. Preparation allergenic pollen extracts; the points should be considered to make high-quality products. I Immunoassay Immunochem 2019; 40: 26-39.

13. Oskouei YM, Hosseini RF, Ahanchian H, et al. Report of common aeroallergens among allergic patients in northeastern Iran. Iran J Otorhinolaryngol 2017; 29: 89-94.

14. Van Cauwenberge P, De Belder T, Vermeiren J, Kaplan A. Global resources in allergy (GLORIA): allergic rhinitis and allergic conjunctivitis. Clin Exp Allergy Rev 2003; 3: 46-50.

15. Bakhshaee M, Jabbari F, Hoseini S, et al. Effect of silymarin in the treatment of allergic rhinitis. Otolaryngol Head Neck Surg 2011; 145: 904-9.

16. Ariaee N, Ghorbani J, Panahi M, et al. Oral administration of Zataria multiflora extract decreases IL-17 expression in perennial allergic rhinitis. Rep Biochem Mol Biol 2018; 6: 203-7.

17. Jalessi M, Farhadi M, Kamrava SK, et al. The reliability and validity of the persian version of sinonasal outcome test 22 (snot 22) questionnaires. Iran Red Crescent Med J 2013; 15: 404-8.

18. Narkus A, Lehnigk $U$, Haefner D, et al. The placebo effect in allergen-specific immunotherapy trials. Clin Transl Allergy 2013; 3: 42.

19. Fässler M, Meissner K, Kleijnen J, et al. A systematic review found no consistent difference in effect between more and less intensive placebo interventions. J Clin Epidemiol 2015; 68: 442-51.
20. Schwartz D, Fischhoff B, Krishnamurti T, Sowell F. The Hawthorne effect and energy awareness. Proc Natl Acad Sci 2013; 110: 15242-6.

21. McCambridge J, Witton J, Elbourne DR. Systematic review of the Hawthorne effect: new concepts are needed to study research participation effects. J Clin Epidemiol 2014; 67: 26777.

22. Boskabady MH, Tabanfar H, Gholamnezhad Z, Sadeghnia HR. Inhibitory effect of Zataria multiflora Boiss and carvacrol on histamine $(\mathrm{H} 1)$ receptors of guinea-pig tracheal chains. Fundamental Clin Pharmacol 2012; 26: 609-20.

23. Boskabady MH, Tabatabaee A, Jalali S. Potential effect of the extract of Zataria multiflora and its constituent, carvacrol, on lung pathology, total and differential WBC, IgE and eosinophil peroxidase levels in sensitized guinea pigs. J Funct Foods 2014; 11: 49-61.

24. Boskabady MH, Mehrjardi SS, Rezaee A, et al. The impact of Zataria multiflora Boiss extract on in vitro and in vivo Th 1/ Th 2 cytokine (IFN- $\gamma /$ IL4) balance. J Ethnopharmacol 2013; 150: 1024-31.

25. Ariaee N, Zarei S, Mohamadi M, Jabbari F. Amelioration of patients with chronic spontaneous urticaria in treatment with vitamin D supplement. Clin Mol Allergy 2017; 15: 22.

26. Khoshkhui M, Alyasin S, Sarvestani EK, et al. Evaluation of serum interleukin-35 level in children with persistent asthma. Asian Pac J Allergy Immunol 2017; 35: 91-5. 